\title{
Dispositional Mindfulness and Relapse Vulnerability as Mediated by Self-Efficacy Among Persons in Recovery From Substance Use Disorders (SUDs)
}

\author{
Niño B. Galacgac \\ Maria Caridad H. Tarroja \\ De La Salle University-Manila
}

\begin{abstract}
The study sought to explain the potential mechanism by which dispositional mindfulness influences relapse vulnerability through self-efficacy among persons in recovery from Substance Use Disorders (SUDs). Data were collected from residential clients $(\mathrm{N}=206)$ in both private and government drug rehabilitation centers. Results of the mediation analysis suggest that the trait of being fully attentive to present experiences allows recovering persons to access functional self-beliefs, such as the perceived capacity to accomplish tasks and overcome difficulties. In the face of challenging situations that may trigger relapse, dispositional mindfulness contributes partially to one's sense of command or mastery. Consequently, this helps individuals cope with relapse problems. The findings provide implications for relapse prevention and the utility of mindfulness-based interventions for SUDs.
\end{abstract}

Keywords: dispositional mindfulness, relapse vulnerability, general self-efficacy, Substance Use Disorders (SUDs)

Substance use disorders (SUDs) are chronic and one of the challenges to their effective treatment is the high tendency to relapse (Mohammadpoorasl et al., 2012). Studies show that a substantial number of people who enter rehabilitation return to substance use after treatment. For example, relapse rates of $25 \%$ to $50 \%$ are observed within two years after short-term treatment, $29 \%$ after three years of

Correspondence concerning this article can be addressed to Niño B. Galacgac. Email:ninogalacgac@yahoo.com 
abstinence, and as much as $25 \%$ even after 15 years of sobriety (Laudet \& White, 2004). In the Philippines, the Dangerous Drugs Board (DDB, 2016) reported readmission rates of $20 \%$ in government residential facilities. Social and environmental factors such as unemployment, relationship problems, stressful life events, substance availability, and the presence of significant others who use substances were identified as common predictors of relapse (Mohammadpoorasl et al., 2012). Likewise, negative emotional states like depression, anger, anxiety, and chronic stress have also been found to influence relapse (Marlatt \& Donovan, 2005).

Currently, relapse studies are shifting to relapse vulnerability, defined as the fear of relapse and the difficulty in maintaining abstinence and the gains experienced during treatment or recovery (Prochaska, Norcross, \& DiClemente, 2005). There has also been a shift towards identifying significant predictors of relapse vulnerability and how these may influence rehabilitation outcomes. Although studies have shown how mindfulness-based interventions can reduce relapse (Witkiewitz, Marlatt, \& Walker, 2005), there is a dearth of literature on the impact of these interventions on relapse vulnerability. A concept related to mindfulness-based interventions is dispositional mindfulness which may be related to relapse vulnerability (Black, Sussman, Johnson, \& Milam, 2012; Garland \& Roberts-Lewis, 2013; Garland, RobertsLewis, Kelley, Tronnier, \& Hanley, 2014 ). Another construct that has been found to be closely related to relapse vulnerability is self-efficacy (Dolan, Martin, \& Rohsenow, 2008; Litt, Kadden, Kabela-Cormier, \& Petry, 2008; Maisto, Connors, \& Zywiak, 2000; Moos \& Moos, 2006; Vielva \& Iraurgi, 2001). This study examined the relationships of dispositional mindfulness, self-efficacy, and relapse vulnerability.

\section{Relapse Vulnerabilityin SUDs and Dispositional Mindfulness}

Recently, there has been growing attention on the potential utility of mindfulness-based relapse prevention modalities for SUDs (Witkiewitz et al., 2005). These interventions are anchored in the concept of mindfulness, conceptualized as non-judgmental attention to and appreciation of experiences in the present moment (Kabat-Zinn \& Hanh, 2009). It involves focusing one's awareness on immediate 
situations and approaching them with openness and curiosity regardless of their valence and desirability (Bishop et al., 2004). Mindfulness allows people to tolerate uncertainty, become more discerning and less reactive, and to engage more meaningfully with their environments (Carson \& Langer, 2006). It is more commonly associated with meditation practices, such as mindfulness meditation and mindful movements (Kabat-Zinn \& Hanh, 2009). Although mindfulness was initially understood as a cognitive state (Langer, 1989) and later on a cognitive style (Sternberg, 2000), more recent conceptualizations also consider mindfulness as an existing trait referred to as dispositional mindfulness.

Dispositional mindfulness is defined as a naturally-occurring trait (Brown \& Ryan, 2004) characterized by the tendency to display present-oriented, unbiased, and tolerant awareness of one's thoughts and feelings in daily life (Baer, Smith, Hopkins, Krietemeyer, \& Toney, 2006). Dispositional mindfulness enables individuals to be fully aware of the present, sustain their attention on day-to-day phenomena, and become receptive of moment to moment experiences (Bishop et al., 2004; Brown \& Ryan, 2004). Although mindful dispositions vary in presentation among people (Walach, Buchheld, Buttenmüller, Kleinknecht, \& Schmidt, 2006), dispositional mindfulness has also been shown to be flexible. This means that it can be strengthened or enhanced through mindfulness-based interventions.

Persons in recovery from SUDs relapse because of intolerable conditions that trigger them to seek immediate relief through substance use (Robinson \& Berridge, 2003). Therefore, the ability to be aware of triggers through dispositional mindfulness helps them employ alternative and adaptive ways of coping (Keng, Smoski, \& Robins, 2011). Some studies relating dispositional mindfulness to treatment outcomes indicate that it enables recovering adults to focus their attention away from cues related to alcohol (Garland, Boettiger, Gaylord, Chanon, \& Howard, 2012). It has also been shown to decrease the likelihood of relapse in smoking (Black et al., 2012) and lower substance craving among people with SUDs (Garland \& Roberts-Lewis, 2013). Nevertheless, there remains a need to further investigate the influence of dispositional mindfulness on relapse vulnerability, and the factors that may mediate this relationship (Garland et al., 2014). 


\section{Self-Efficacy as a Mediator in SUDs Treatment and Outcomes}

The role of self-efficacy in curbing addictive behaviors has already been demonstrated in numerous studies. However, the mechanisms through which self-efficacy works in psychological treatments for SUDs has yet to be fully understood (Kadden \& Litt, 2011). Self-efficacy, as defined by Bandura (1977), is an individual's set of beliefs in one's capability to accomplish tasks successfully. It also involves being able to carry out necessary behaviors in achieving desired outcomes. The strength of these beliefs is an influential factor in coping with stress. Bandura (1977) stated, "efficacy expectations are a major determinant of people's choice of activities, how much effort they will spend, and how long they will sustain the effort in dealing with stressful situations" (p. 194). In SUDs, self-efficacy has been found to be related with relapse tendencies in alcohol and drug abuse three months (Dolan et al., 2008), six months (Vielva \& Iraurgi, 2001), a year (Litt et al., 2008; Maisto et al., 2000), and even three years (Moos \& Moos, 2006) after rehabilitation.

Despite the extensive research on the role of self-efficacy in the relapse of SUDs, several limitations have been observed. Firstly, the majority of studies have examined posttreatment self-efficacy and the relapse process at different points in time after rehabilitation. Varied results may be attributed to inconsistent measurement points and the lack of agreement on the operationalization of relapse. This implies the need to shift from posttreatment relapse to relapse vulnerability in rehabilitation. Secondly, a lot of studies on self-efficacy in SUD relapse have focused mainly on domain-specific beliefs directly related to addictive behaviors (e.g., abstinence self-efficacy, drug avoidance selfefficacy, etc.). Fewer studies have focused on self-efficacy as a general confidence in one's own capability (Schwarzer \& Jerusalem, 1995) and the capacity to execute effective behaviors across various situations (Judge, Erez, \& Bono, 1998). General self-efficacy is understood as a belief in one's potential to function effectively and overcome challenges across different tasks (DeRue \& Morgeson, 2007). With regard to SUDs, there appears to be a need to examine general selfefficacy (GSE) to explain behavior in contexts or spheres of functioning that may not be directly related to SUDs (Luszczynska, Gutierrez- 
Dona, \& Schwarzer, 2005; Scholz, Doña, Sud, \& Schwarzer, 2002). Third, research results show inconsistent findings on the association between self-efficacy and relapse (Wong et al., 2004). In other studies, self-efficacy is not a straightforward predictor of outcomes; rather, it is moderated by factors such as cognitive impairment (Bates, Pawlak, Tonigan, \& Buckman, 2006) and quality of the therapeutic relationship (Ilgen, McKellar, \& Tiet, 2006). Thus, research efforts are now directed towards explaining whether self-efficacy operates as a consequence of other distal factors or is a mechanism in behavior change among people with SUDs.

Finally, there have been few studies that examined the potential mediating role of self-efficacy on SUDs outcomes. Specifically, selfefficacy has been found to mediate the effects of group motivational therapy on drinking outcomes (LaChance, Feldstein Ewing, Bryan, \& Hutchison, 2009) and marijuana use (Litt, Kadden, \& Stephens, 2005). Likewise, self-efficacy has been found to intervene in the outcomes of cognitive-behavioral therapy (Brown, Seraganian, Tremblay, \& Annis, 2002), 12-step method of rehabilitation (Aase, Jason, \& Robinson, 2008), and relapse prevention treatment program (Allsop, Saunders, \& Phillips, 2000). However, its mediating role remains to be inconclusive as literature reveals mixed results. In one study, selfefficacy failed to moderate the relationship between treatment and coping skills and the incidence of relapse among marijuana users (Maisto et al., 2000). Another study reported that self-efficacy did not moderate the relationship between goals set by persons in recovery and the accomplishment of these goals (Lozano \& Stephens, 2010).

\section{Mindfulness and Conceptualizations of the Self: The Disposition's Link to Self-Efficacy}

Extant literature has established a relationship between selfefficacy and relapse in SUDs. Previous studies consider self-efficacy as a predictor of relapse or a factor that mediates the outcomes of treatment. Likewise, dispositional mindfulness has been evidenced to predict behaviors related to substance use and abuse. However, no research has directly investigated the possibility that self-efficacy may account for the underlying mechanism that would explain 
how dispositional mindfulness influences SUDs outcomes such as relapse vulnerability. This attempt is of considerable value, not only for its theoretical contribution, but also for its possible utility in clinical practice. Nevertheless, a number of theoretical and empirical accounts have already been forwarded in the literature that explain the relationship between dispositional mindfulness, self-efficacy, and relapse vulnerability.

A framework of self-awareness, -regulation, and -transcendence (S-ART) introduced by Vago and Silbersweig (2012) argued that mindfulness provides insight into the true nature of the self. The S-ART model theorized that a high level of mindfulness promotes adaptive self-appraisals by inhibiting persistent cognitive beliefs about the self. These beliefs are patterns of thought that affect how a person perceives and relates to the world with the most central beliefs being those held about the self. Mindfulness is supposed to provide "phenomenal clarity" that would allow a person to have more precise self-perceptions. The accuracy of these perceptions weakens cognitive biases that may surface during the experience of stressful situations or adverse events. In turn, this would allow more useful and effective cognitive and behavioral reactions to transpire.

This has been supported by evidence presented by Hanley et al. (2015) that suggests that mindfulness as a trait is linked to more malleable schemas about the self. When there is awareness of the present moment, mindful individuals develop evaluations about the self that are adaptive and not influenced by biased or rigid beliefs. Moreover, dispositional mindfulness leads one to become more open to bodily-sensory, mental, and emotional experiences (Shapiro, Carlson, Astin, \& Freedman, 2006). Those with a high level of mindfulness welcome these cues rather than trying to change things they cannot control. Further, recent empirical evidence provided by Hanley and Garland (2017) suggests that behaving with increased awareness substantially leads to a clearer concept of the self. Hence, acting mindfully and intentionally give rise to self-concept beliefs that may subsequently result in more stable behavioral tendencies.

Taken together and applied in the context of relapse in SUDs, it may be inferred that during high-risk or stressful situations, dispositional mindfulness allows persons in recovery to take a moment of stillness 
and awareness. This may subsequently provide them access to adaptive beliefs about the self (i.e., self-efficacy), allowing them to feel a sense of control or mastery. Hence, they may resort to more effective ways of coping rather than returning to substance use to reduce distress or regain command.

\section{The Present Study}

The present study sought to explain how dispositional mindfulness influences relapse vulnerability, and the role of self-efficacy in mediating the relationship between dispositional mindfulness and relapse vulnerability. It is hypothesized that (1) dispositional mindfulness is negatively related to relapse vulnerability; (2) dispositional mindfulness is positively related to self-efficacy; (3) selfefficacy is negatively related to relapse vulnerability; and that (4) selfefficacy mediates the relationship between dispositional mindfulness and relapse vulnerability.

\section{METHOD}

This study employed a multivariate correlational research design. The survey method was used to collect data.

\section{Participants}

The participants were residential/in-patient clients $(N=206)$ who were diagnosed with substance use disorders (SUDs) in both private and government drug rehabilitation centers. They were: (1) at least 21 years of age, (2) able to read and understand basic Filipino language, (3) in treatment for at least three months, (4) not diagnosed with psychiatric disorders with psychotic features, and (5) not receiving medical treatment for other disorders aside from their SUDs. The final sample consisted of male ( $n=122,59.22 \%)$ and female $(n=84,40.78 \%)$ residential clients whose ages range from 21-61 years old ( $M=35.67$, $S D=9.0$ ). Most of them are married (either legally or consensually, $n=96,46.60 \%$ ) and have completed basic education (i.e., elementary or high school, $n=134,65.05 \%)$. The majority were employed either on 
a full-time or part-time basis ( $n=123,59.71 \%)$ before their admission to the rehabilitation center.

Most of the participants were polysubstance users $(n=138,67 \%)$ with methamphetamine hydrochloride (shabu) and alcohol being the most common choices of substance $(n=132,64.08 \% ; n=127,61.65 \%$, respectively). On the other hand, most monosubstance users ( $n=68$, $33 \%)$ exclusively used shabu $(\mathrm{n}=63,30.58 \%)$. Shabu and alcohol appeared to be the substances mostly used for a considerable length of time ( $M=93.24$ months, $S D=89.99 ; M=80.80$ months, $S D=95.05$, respectively). Most of them attempted to quit their substance use ( $n=165,80.1 \%$ ), but about a third of those who tried to stop experienced one to three relapse episodes ( $n=73,35.4 \%)$, with duration of sustained abstinence ranging from one month to 10 years $(M=15.64$ months, $S D=24.22)$.

In addition, participants also reported that they have experienced several problems consequent to their substance use. Majority reported family problems ( $n=135,65.53 \%$ ) such as marital discord and conflict with significant others. Some had problems related to work $(n=61$, 29.61\%) such as tardiness, absenteeism, and low motivation and poor performance. Others had financial difficulties ( $n=89,43.2 \%)$ such as impulsive spending and accumulating debts. Relationship problems ( $n=44,21.36 \%)$ pertaining to conflicts with neighbors and community members were also common. Few reported somatic symptoms $(n=5$, $2.433 \%$ ) such as headaches, dizziness, and nausea. A number of the participants were under alternative sentencing for legal issues $(n=30$, $14.56 \%$ ) brought about by criminal offenses incurred because of their substance use.

The sample was dominated by residential clients from government-funded rehabilitation facilities $(n=167,81.07 \%)$. They reported willingness to undergo treatment ( $n=199,96.60 \%)$ mainly due to a personal decision to change ( $n=95,46.12 \%)$. Majority of the participants were admitted to the rehabilitation facility for the first time ( $n=182,88.35 \%$ ), whereas most of those who had past rehabilitation experience $(n=24,11.65 \%)$ had been admitted once or twice $(n=21.19 \%)$ prior to their current admission. Length of stay in their present rehabilitation facility ranged from three months up to one and a half year $(M=4.83$ months, $S D=2.06)$. Furthermore, they 
reported participation in different rehabilitation activities within their respective centers including religious activities $(n=137,66.50 \%)$, seminars ( $n=150,28.55 \%$ ), and group counseling ( $n=89,43.20 \%)$.

\section{Instruments}

Dispositional mindfulness. The Mindful Attention Awareness Scale (MAAS; Brown \& Ryan, 2003) was used to measure dispositional mindfulness. It is designed to assess responsive consciousness and attention to present, day-to-day experiences. The scale consists of 15 items answered using a 6-point Likert scale from 1 (almost always) to 6 (almost never) yielding a single total score. The Cronbach's $\alpha$ of the scale in this study is .89.

Relapse vulnerability. The Struggle to Maintain Abstinence subscale of the University of Rhode Island Change AssessmentDrug Version (URICA; Carbonari et al., 1994) was used to measure relapse vulnerability. The scale is a 28 -item inventory which measures client's motivation to change through the course of drug rehabilitation treatment. On the other hand, the subscale used in the study is composed of eight items rated using a 5-point Likert scale ranging from 1 (strongly disagree) to 5 (strongly agree). Higher scores mean increased vulnerability to relapse. In this study, the internal consistency of the scale is $\alpha=.71$.

General self-efficacy. The variable was measured using the General Self-Efficacy (GSE) Scale (Schwarzer \& Jerusalem, 1995). The 10-item measure assesses a person's global credence in one's capacity to successfully behave in challenging situations, control environmental demands, and handle various obstacles. A total score is obtained by summing up the four-choice response from 1 (Not true at all) to 4 (Exactly true). In this study, Cronbach's $\alpha$ for GSE is .87 .

Prior to the collection of data, research instruments were first translated to Filipino. To ensure that the instruments are in their equal form, a pilot test was conducted with undergraduate students $(N=60)$ from a private college. Scores obtained from both translations were analyzed and results showed that scores for the original and translated instruments were significantly correlated (MAAS: $r=.78$, $p<.001$; URICA: $r=.81, p<.001$; GSE: $r=.84, p<.001$ ) and that they 
have demonstrated acceptable levels of internal consistency (MAAS: $\alpha=.88$; URICA: $\alpha=.87$; GSE: $\alpha=.86$ ).

\section{Data Gathering Procedures}

The research complied with the ethical guidelines prescribed by the Research Ethics Office of the university. Four drug rehabilitation centers responded to the request for data collection. Eligible participants selected by respective center psychologists were oriented about the objectives of the study and informed consent was likewise obtained. Survey questionnaires were group-administered, and the collected data were tallied and analyzed. The anonymity of individuals and institutions was protected and data was stored in a passwordprotected file to ensure the confidentiality of obtained information.

\section{Data Analysis}

Mediation analysis (Hayes, 2009) was used to evaluate the main proposition that self-efficacy intervenes in the relationship between dispositional mindfulness and relapse vulnerability. The accurate estimate of the indirect effect (path a and path b) and its statistical significance was analyzed using the bootstrapping method included in PROCESS, a macro plug-in developed by Preacher and Hayes (2008) for SPSS.

Prior to the main analysis, entry errors were corrected and respondents with patterned responses $(n=4)$ were removed from the data set. Also, mean substitution was utilized to replace missing entries and outliers were deleted from the sample $(n=4)$. Succeeding analyses used parametric tests since assumptions of data normality were evidenced by the Shapiro Wilk Test and of the generated histogram and Q-Q plots.

\section{RESULTS}

Results in Table 1 suggest moderately high scores for dispositional mindfulness. On the other hand, relapse vulnerability conceptualized as the struggle or difficulty in maintaining abstinence and the fear of 


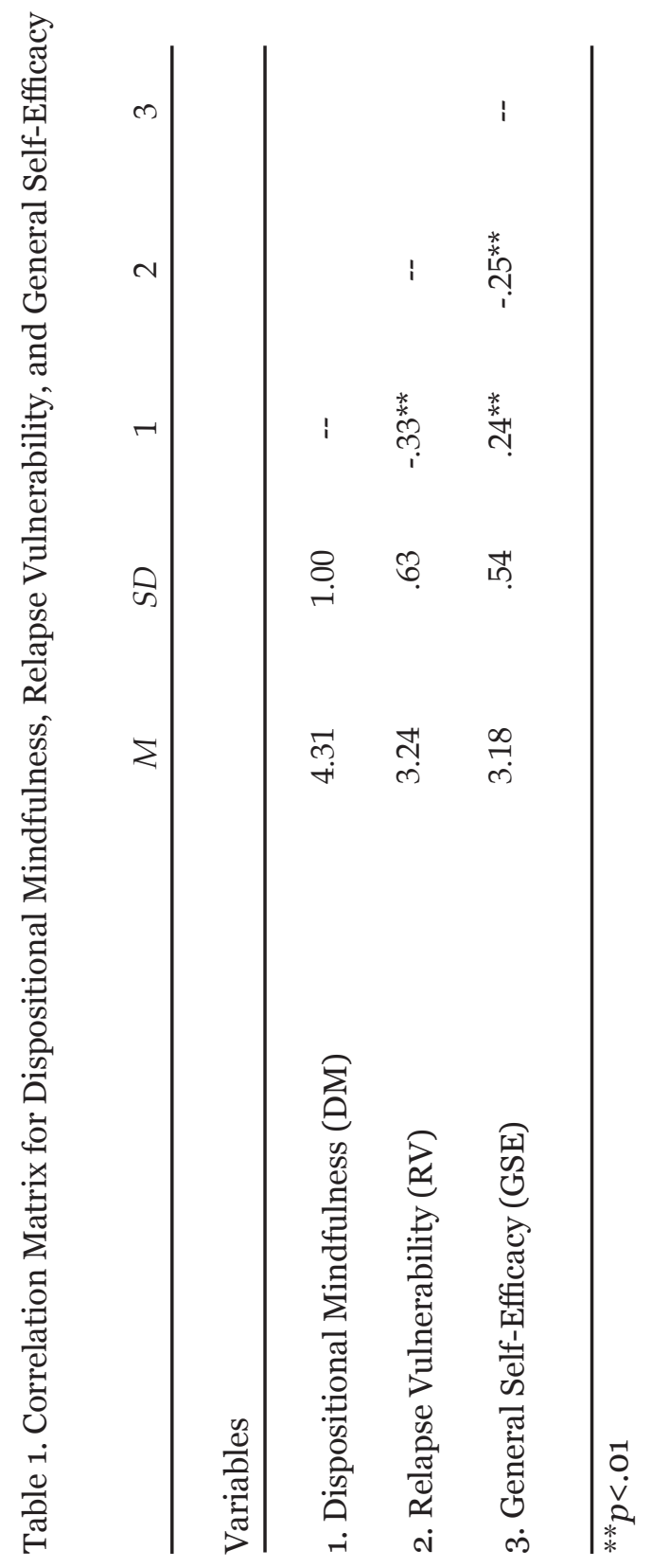


relapse is moderately low ( $M d n=3.38)$. Likewise, general self-efficacy, which refers to a person's set perceived capability to accomplish tasks successfully, is moderately low ( $M d n=3 \cdot 38)$.

Dispositional mindfulness has an inverse relationship with relapse vulnerability and a positive relationship with general selfefficacy. On the other hand, an inverse correlation was found between relapse vulnerability and general self-efficacy. This suggests that people in recovery who have higher dispositional mindfulness tend to struggle less in maintaining sobriety and have stronger beliefs in their competence to stay sober. Moreover, higher report of self-efficacy is associated to lower relapse vulnerability among people recovering from substance use disorders.

The proposed mediation model was examined to test the possible underlying mechanism by which dispositional mindfulness influences relapse vulnerability through self-efficacy. Figure 1 shows the result of mediation analysis.

Results revealed that dispositional mindfulness is negatively associated with relapse vulnerability and positively related to general self-efficacy. The mediator, general self-efficacy, is negatively associated with relapse vulnerability. It further showed that the direct effect of dispositional mindfulness on relapse vulnerability remains significant but is reduced when controlling for self-efficacy. In other words, dispositional mindfulness is indirectly associated with relapse vulnerability via general self-efficacy, with an indirect effect estimate of -.029 and a 95\% bootstrap confidence interval of -.067 to -.013. This is also confirmed by a Sobel test $(z=-2.20)$. The effect size $\left(r^{2}=.17\right)$ is between medium and large (Kenny, 2016).

\section{DISCUSSION}

\section{Dispositional Mindfulness and Relapse Vulnerability}

One of the important findings of this study is the mechanism by which dispositional mindfulness impacts relapse vulnerability. The study validates the literature on the metareflective capacity of dispositional mindfulness (Teasdale, Segal, \& Williams, 1995). This mechanism aids people in focusing their attention on the present 


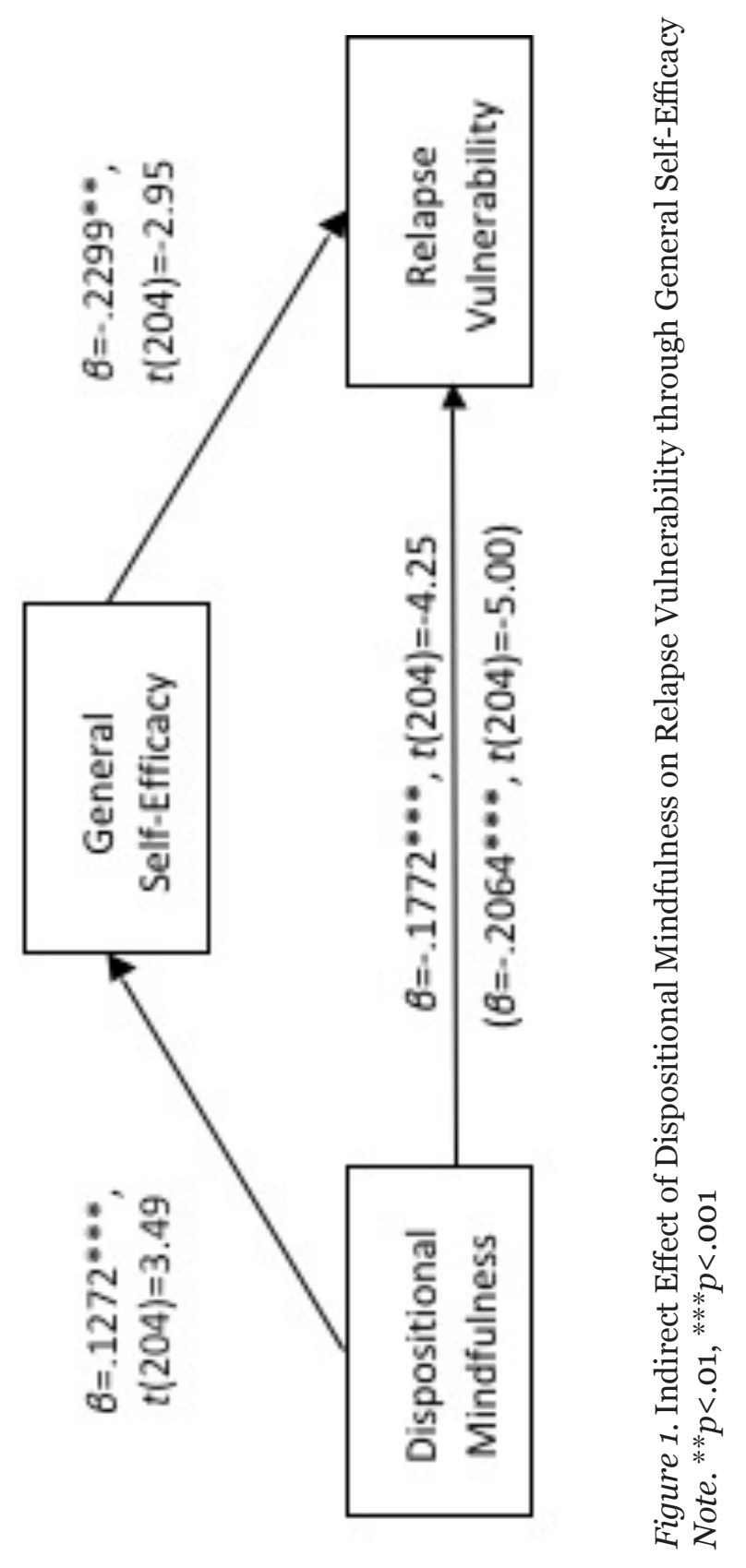


moment but also to recognize and accept symptoms that may be difficult to change (Kohls, Saver, \& Walach, 2009; Wallace \& Shapiro, 2006) through a sustained process of thinking and analyzing. Dispositional mindfulness as an inherent characteristic allows people to be more flexible, less reactive, and more analogical and critical with their thoughts (Carson \& Langer, 2006). It allows people with SUDs to put aside time to think things through, eventually decide to stop abusing substances, and to abstain permanently. It can be noted that the participants' reported level of dispositional mindfulness is moderately high and that the majority have actually attempted to quit using substances, are willing to undergo rehabilitation, and have sought treatment.

The results support previous findings that dispositional mindfulness is related to lower cravings of substances (Garland \& Roberts-Lewis, 2013) and decreased reactivity to alcohol cues (Garland et al., 2012), relapse to smoking (Black et al., 2012), and even of lifetime substance use (Eisenlohr-Moul, Walsh, Charnigo, Lynam, \& Baer, 2012). However, results are in contrast to results of other studies that reported that mindfulness is positively correlated to heavy substance use (Leigh, Bowen, \& Marlatt, 2005) and that behaving with awareness is associated with alcohol use (Leigh \& Neighbors, 2009). It is important to take note that these contrasting pieces of evidence were observed in mostly university student samples who were not in treatment and whose levels of use of substances are sub-clinical. The present study that involved residential clients diagnosed with SUDs confirms findings of studies with similar treatment-seeking population (Garland et al., 2012 ) and clinical sample (Dakwar, Mariani, \& Levin, 2011) that trait mindfulness is inversely related to substance craving. In addition, the study extends the literature because it examined vulnerability to relapse instead of the actual number of relapse episodes, which is the common method among many relapse studies. This approach acknowledges the notion that despite being confined in a highly-controlled or structured environment (i.e., rehabilitation centers), persons undergoing treatment for SUDs experience anxiety, fear, craving, and difficulty in sustaining change. 


\section{Self-Efficacy and Relapse Vulnerability}

With regard to self-efficacy and relapse vulnerability, results indicate that a heightened general belief in one's capability is related to diminished struggles in maintaining abstinence and lesser fear of relapse. Since self-efficacy is understood to influence people's choice of activities and the effort they sustain during stressful situations (Bandura, 1977), it is expected to predict effective adjustment and competent problem-solving. Despite the reported attempts of the majority of the participants to abstain and to undergo rehabilitation, they experienced several relapse episodes in recovery. It can be noted as well that the level of general self-efficacy reported by the participants is moderately low and that their substance use has indeed resulted in considerable life problems. These observations demonstrate that in spite of the attempt to abstain, the participants may still lack sufficient self-efficacy needed to maintain abstinence and manage relapse triggers.

In the context of SUDs, the findings are congruent with previous assertions that self-efficacy predicts relapse at various stages of recovery in alcohol (Lozano \& Stephen, 2010), marijuana (Litt et al., 2008), cocaine (Dolan et al., 2008), and even with polysubstance users (Litt et al., 2008). The current work recognizes the function of self-efficacy in general, in contrast with previous studies that looked into more context-specific efficacy beliefs related to substance use (Demmel, Nicolai, \& Jenko, 2006; Silverman, 2014; Zimmerman \& Cleary, 2006). This suggests that persons in recovery may utilize both forms of efficacy beliefs in dealing with stressors that may either be directly or indirectly related to substance use. For example, the efficacy belief that "I can successfully refrain from taking drugs" which is more specific to substance use, and the essentially broader "I can handle whatever comes my way," may both function to indicate beliefs that would cut across many other areas of a person's functioning. As in the case with dispositional mindfulness, self-efficacy in this study is associated with vulnerability to relapse rather than actual relapse episodes, which both validates and extends existing literature. 


\section{Self-Efficacy as Mediator Between Dispositional Mindfulness and Relapse Vulnerability}

Further, the results established a positive association between dispositional mindfulness and self-efficacy, providing support to extant literature that explain how these two traits are interrelated. Results of the present study suggest that heightened mindfulness relates to functional self-evaluation, such as self-efficacy beliefs. This surfaces from a phenomenal clarity induced by being fully aware of moment-to-moment experiences. Dispositional mindfulness weakens "automatic" personal biases or rigid beliefs that are usually accessed during stressful situations which, in turn, lead to dysfunctional cognitive and behavioral responses. As trait mindfulness becomes higher, one becomes more accepting of sensory, mental, and emotional experiences that equate to fewer struggles in trying to get control of a situation.

The findings of the current work confirm the feasibility of the proposed model presenting the mechanism by which dispositional mindfulness influences relapse vulnerability through self-efficacy. As hypothesized, the trait of being fully attentive to present experiences allows people recovering from SUDs to attain a state of stillness and awareness. This condition makes them access functional perceptions about the self, such as the perceived capacity to accomplish tasks and overcome difficulties. In the face of challenging situations that may trigger relapse, dispositional mindfulness contributes partially to one's sense of command or mastery. Consequently, the heightened selfefficacy helps individuals to respond more constructively by employing helpful ways of coping. Usually, people in recovery would rather resort to an automatic response (i.e., reverting to substance use) in order to diminish distress or gain control over a stressful experience. In other words, dispositional mindfulness reduces relapse vulnerability through a person's heightened self-efficacy beliefs to handle obstacles and behave successfully in challenging situations during recovery.

It is necessary to take note, however, that this intervening pathway is partial, and the relationship may still be explained by other variables operating in alternative paths not covered in this study. Even so, the moderate to slightly large indirect effect is substantial and warrants 
significant attention and further investigation.

\section{Implications on Clinical Practice}

The findings of the study have implications on clinical practice, specifically in terms of relapse prevention and the utility of mindfulnessbased interventions for SUDs. Given the chronicity of SUDs and the high tendency of relapse, professionals and programs may need to anticipate the likelihood of several relapse episodes before attaining long-term maintenance. The complex process of change that clients go through must be acknowledged, including episodes of craving even in highly-controlled rehabilitation centers. Relapse vulnerabilities, as well as the levels of dispositional mindfulness of clients, can be assessed early in and during treatment. Those who are most at risk of relapse and who will benefit most from relapse-preventive interventions (Bauer, 2001) may be identified. Currently, most relapse prevention programs (at least for the centers surveyed in this research) are offered towards the end or completion of rehabilitation. By recognizing that vulnerability to relapse can be examined by looking at struggles, craving and urges, and fears, it could allow prevention work to be introduced at different points or levels of the treatment. Persons who appear to have higher risks for relapse to substance use may be identified for more individualized or intensive interventions. This anticipation may minimize clients' shame and therapists' guilt and frustration over the tendency to relapse and counter the unrealistic expectation of a linear progression or complete recovery after treatment (Prochaska et al., 2005).

Further, this study renders empirical support to mechanisms explaining the utility of mindfulness-based treatment modalities for relapse of SUDs (e.g., Mindfulness-Based Relapse Prevention). Because dispositional mindfulness can be strengthened or enhanced through mindfulness-based interventions or training (Carmody \& Baer, 2008), participation in activities such as meditation leads to a significant increase in trait mindfulness and efficacy beliefs. Although specific self-efficacy enhancement strategies are already placed in treatment (i.e., praising clients, recognizing small steps toward positive change) this study provides evidence that mindfulness itself may 
already have an implicit and partial influence to efficacy beliefs. This process revealed in the current work is not yet part of rehabilitation programs commonly utilized at least in the centers surveyed. Hence, mindfulness training may be introduced to augment services already in place for residential clients.

\section{Limitations and Directions for Future Research}

The primary limitation of the study is the possible effect of social desirability and impression management bias in self-report. Especially for participants with SUDs, social desirability has been found to substantially exaggerate reports of willingness to change and diminished admission of substance-related problems (Zemore, 2012). For example, despitebriefing the participants about research objectives, some would still ask if their answers would determine treatment decisions about them. This could have made participants respond in a desirable manner thus influencing the accuracy and truthfulness of the collected data. Future studies may consider incorporating measures of social desirability and account for its possible effect on the evaluation of the variables of interest.

Another limitation is that the design does not allow for causal explanations of the relationships between the variables. Future research may want to examine the feasibility of the proposed model by utilizing experimental or longitudinal designs. Through more rigorous methodologies, changes in dispositional mindfulness, selfefficacy, and relapse vulnerability as actual effects of mindfulnessbased interventions may be established. Additionally, expanding the generalizability of this model to apply to other forms of addiction other than SUDs can be forwarded by further research.

\section{Conclusion}

The findings of the current work contribute to the growing body of literature directed towards understanding relapse, the mounting interest in the study of dispositional mindfulness, and the role of selfefficacy in SUDs. The mediation model forwarded in this research identifies dispositional mindfulness as a pre-treatment individual 
trait that can be potentially targeted by rehabilitation interventions to enhance self-efficacy. Nevertheless, a lot of work still needs to be done to continue addressing relapse as a key challenge in the effective treatment of substance use disorders.

\section{REFERENCES}

Aase, D. M., Jason, L. A., \& Robinson, W. L. (2008). 12 -step participation among dually-diagnosed individuals: A review of individual and contextual factors. Clinical Psychology Review, 28(7), 1235-1248.

Allsop, S., Saunders, B., \& Phillips, M. (2000). The process of relapse in severely dependent male problem drinkers. Addiction, 95(1), 95-106.

Baer, R. A., Smith, G. T., Hopkins, J., Krietemeyer, J., \& Toney, L. (2006). Using self-report assessment methods to explore facets of mindfulness. Assessment, 13, 27-45.

Bandura, A. (1977). Self-efficacy: Toward a unifying theory of behavioral change. Psychological Review, 84(2), 191.

Bates, M. E., Pawlak, A. P., Tonigan, J. S., \& Buckman, J. F. (2006). Cognitive impairment influences drinking outcome by altering therapeutic mechanisms of change. Psychology of Addictive Behaviors, 20(3), 241.

Bauer, L. O. (2001). Predicting relapse to alcohol and drug abuse via quantitative electroencephalography. Neuropsychopharmacology, 25(3), 332-340.

Bishop, S. R., Lau, M., Shapiro, S., Carlson, L., Anderson, N. D., Carmody, J., \& Devins, G. (2004). Mindfulness: A proposed operational definition. Clinical psychology: Science and practice, 11(3), 230-241.

Black, D. S., Sussman, S., Johnson, C. A., \& Milam, J. (2012). Testing the indirect effect of trait mindfulness on adolescent cigarette smoking through negative affect and perceived stress mediators. Journal of Substance Use, 17(5-6), 417-429.

Brown, K. W., \& Ryan, R. M. (2003). The benefits of being present: Mindfulness and its role in psychological well-being. Journal of 
Personality and Social Psychology, 84(4), 822.

Brown, K. W., \& Ryan, R. M. (2004). Perils and promise in defining and measuring mindfulness: Observations from experience. Clinical Psychology: Science and Practice, 11(3), 242-248.

Brown, T. G., Seraganian, P., Tremblay, J., \& Annis, H. (2002). Process and outcome changes with relapse prevention versus 12step aftercare programs for substance abusers. Addiction, 97(6), 677-689.

Carmody, J., \& Baer, R. A. (2008). Relationships between mindfulness practice and levels of mindfulness, medical and psychological symptoms and well-being in a mindfulness-based stress reduction program. Journal of Behavior Medicine, 31(1), 23-33.

Carson, S. H., \& Langer, E. J. (2006). Mindfulness and self-acceptance. Journal of Rational-Emotive \& Cognitive-Behavior Therapy, 24, 29-43.

Dakwar, E., Mariani, J. P., \& Levin, F. R. (2011). Mindfulness impairments in individuals seeking treatment for substance use disorders. The American Journal of Drug and Alcohol Abuse, 37(3), 165-169.

Dangerous Drugs Board. (2016, August 26). 2015 statistics. Retrieved from https://www.ddb.gov.ph/research-statistics/statistics/45research-and-statistics/287-2015-statistics

Demmel, R., Nicolai, J., \& Jenko, D. M. (2006). Self-efficacy and alcohol relapse: Concurrent validity of confidence measures, self-other discrepancies, and prediction of treatment outcome. Journal of Studies on Alcohol, 67(4), 637-641.

DeRue, D. S., \& Morgeson, F. P. (2007). Stability and change in person-team, and person-role fit over time: The effects of growth satisfaction, performance, and general self-efficacy. Journal of Applied Psychology, 92(5), 1242-1253.

Dolan, S. L., Martin, R. A., \& Rohsenow, D. J. (2008). Self-efficacy for cocaine abstinence: Pretreatment correlates and relationship to outcomes. Addictive Behaviors, 33(5), 675-688.

Eisenlohr-Moul, T. A., Walsh, E. C., Charnigo, R. J., Lynam, D. R., \& Baer, R. A. (2012). The "what" and the "how" of dispositional mindfulness using interactions among subscales of the five-facet mindfulness questionnaire to understand its relation to substance 
use. Assessment, 19(3), 276-286.

Garland, E. L., Boettiger, C. A., Gaylord S., Chanon, V. W., Howard, M. O. (2012). Mindfulness is inversely associated with alcohol attentional bias among recovering alcohol-dependent adults. Cognitive Therapy and Research, 36(5), 441-450.

Garland, E. L., \& Roberts-Lewis, A. (2013). Differential roles of thought suppression and dispositional mindfulness in posttraumatic stress symptoms and craving. Addictive Behaviors, 38(2), 1555-1562.

Garland, E. L., Roberts-Lewis, A., Kelley, K., Tronnier, C., \& Hanley, A. (2014). Cognitive and affective mechanisms linking trait mindfulness to craving among individuals in addiction recovery. Substance Use \& Misuse, 49(5), 525-535.

Hanley, A., Garland, E., Canto, A., Warner, A., Hanley, R., Dehili, V., \& Proctor, A. (2015). Dispositional mindfulness and bias in selftheories. Mindfulness, 6(2), 202-207.

Hanley, A. W., \& Garland, E. L. (2017). Clarity of mind: Structural equation modeling of associations between dispositional mindfulness, self-concept clarity and psychological wellbeing. Personality and Individual Differences, 106, 334-339.

Hayes, A. F. (2009) Beyond Baron and Kenny: Statistical mediation analysis in the new millennium. Communication Monographs, $76(4), 408-420$.

Ilgen, M., McKellar, J., \& Tiet, Q. (2006). Abstinence self-efficacy and abstinence 1 year after substance use disorder treatment. Journal of Consulting and Clinical Psychology, 73(6), 1175.

Judge, T. A., Erez, A., \& Bono, J. E. (1998). The power of being positive: The relation between positive self-concept and job performance. Human Performance, 11(2/3), 167-187.

Kabat-Zinn, J., \& Hanh, T. N. (2009). Full catastrophe living: Using the wisdom of your body and mind to face stress, pain, and illness. New York: Delta.

Kadden, R. M., \& Litt, M. D. (2011). The role of self-efficacy in the treatment of substance use disorders. Addictive Behaviors, 36(12), 1120-1126.

Keng, S., Smoski, M. J., \& Robins, C. J. (2011). Effects of mindfulness on psychological health: A review of empirical studies. Clinical Psychology Review, 31(6), 1041-1056. 
Kenny, D. A. (2016). Mediation. Retrieved from http://davidakenny. net $/ \mathrm{cm} /$ mediate.htm

Kohls, N., Saver, S., \& Walach, H. (2009). Facets of mindfulness: An online study investigating the Freiburg Mindfulness Inventory. Personality and Individual Differences, 46,224-230.

LaChance, H., Feldstein Ewing, S. W., Bryan, A. D., \& Hutchison, K. E. (2009). What makes group MET work? A randomized controlled trial of college student drinkers in mandated alcohol diversion. Psychology of Addictive Behaviors, 23(4), 598.

Langer, E. J. (1989). Mindfulness. Cambridge, United States: Addison Wesley Longman.

Laudet, A., \& White, W. (2004). An exploration of relapse patterns among former poly-substance users. Paper session presented at 132nd Annual Meeting of the American Public Health Association, Washington DC, 2004. Washington DC .

Leigh, J., Bowen, S., \& Marlatt, G. A. (2005). Spirituality, mindfulness and substance abuse. Addictive Behaviors, 30(7),1335-1341.

Leigh, J., \& Neighbors, C. (2009). Enhancement motives mediate the positive association between mind/body awareness and college student drinking. Journal of Social and Clinical Psychology, 28(5), 650-669.

Litt, M. D., Kadden, R. M., Kabela-Cormier, E., \& Petry, N. M. (2008). Coping skills training and contingency management treatments for marijuana dependence: Exploring mechanisms of behavior change. Addiction, 103(4), 638-648.

Litt, M. D., Kadden, R. M., \& Stephens, R. S. (2005). Coping and selfefficacy in marijuana treatment: Results from the Marijuana Treatment Project. Journal of Consulting and Clinical Psychology, 73(6), 1015.

Lozano, B. E., \& Stephens, R. S. (2010). Comparison of participatively set and assigned goals in the reduction of alcohol use. Psychology of Addictive Behaviors, 24(4), 581.

Luszczynska, A., Gutierrez-Dona, B., \& Schwarzer, R. (2005). General self-efficacy in various domains of human functioning: Evidence from five countries. International Journal of Psychology, 4O(2), 80-89.

Maisto, S. A., Connors, G. J., \& Zywiak, W. H. (2000). Alcohol 
treatment changes in coping skills, self-efficacy, and levels of alcohol use and related problems 1 year following treatment initiation. Psychology of Addictive Behaviors, 14(3), 257.

Marlatt, G. A., \& Donovan, D. M. (Eds.). (2005). Relapse prevention: Maintenance strategies in the treatment of addictive behaviors. New York: Guilford Press.

Mohammadpoorasl, A., Fakhari, A., Akbari, H., Karimi, F., Bostanabad, M. A., Rostami, F., \& Hajizadeh, M. (2012). Addiction relapse and its predictors: A prospective study. Journal of Addiction Research \& Therapy, 3(1), 1-3.

Moos, R. H., \& Moos, B. S. (2006). Rates and predictors of relapse after natural and treated remission from alcohol use disorders. Addiction, 101(2), 212-222.

Preacher, K. J., \& Hayes, A. F. (2008). Asymptotic and resampling strategies for assessing and comparing indirect effects in multiple mediator models. Behavior Research Methods, 4O(3), 879-891.

Prochaska, J. O., Norcross, J. C., \& DiClemente, C. C. (2005). Stages of change: Prescriptive guidelines. In G. P. Koocher, J. C. Norcross, \& S. S. Hill (Eds.), Psychologists' desk reference (2nd ed., pp.443448). New York: Oxford.

Robinson, T. E., \& Berridge, K. C. (2003). Addiction. Annual Review of Psychology, 54(1), 25-53.

Scholz, U., Doña, B. G., Sud, S., \& Schwarzer, R. (2002). Is general self-efficacy a universal construct? Psychometric findings from 25 countries. European Journal of Psychological Assessment, 18(3), 242-251.

Schwarzer, R., \& Jerusalem, M. (1995). Generalized self-efficacy scale. In J. Weinman, S. Wright, \& M. Johnsston (Eds.), Measures in health psychology: A user's portfolio (pp. 35-37). Windsor, England: NFER-Nelson.

Shapiro, S. L., Carlson, L. E., Astin, J. A., \& Freedman, B. (2006). Mechanisms of mindfulness. Journal of Clinical Psychology, 62(3), 373-386.

Silverman, M. J. (2014). Effects of music therapy on drug avoidance self-efficacy in patients on a detoxification unit: A threegroup randomized effectiveness study. Journal of Addictions Nursing, 25(4), 172-181. 
Sternberg, R. J. (2000). Images of mindfulness. Journal of Social Issues, 56(1), 11-26.

Teasdale, J. D., Segal, Z., \& Williams, J. M. G. (1995). How does cognitive therapy prevent depressive relapse and why should attentional control (mindfulness) training help? Behaviour Research and Therapy, 33(1), 25-39.

Vago, D. R., \& Silbersweig, D. A. (2012). Self-awareness, self-regulation, and self-transcendence (S-ART): A framework for understanding the neurobiological mechanisms of mindfulness. Frontiers in Human Neuroscience, 6, 296.

Vielva, I., \& Iraurgi, I. (2001). Cognitive and behavioural factors as predictors of abstinence following treatment for alcohol dependence. Addiction, 96(2), 297-303.

Walach, H., Buchheld, N., Buttenmüller, V., Kleinknechtc, N., \& Schmidta, S. (2006). Measuring mindfulness-the Freiburg Mindfulness Inventory. Personality and Individual Differences, 4O(8), 1543-1555.

Wallace, B. A., \& Shapiro, S. L. (2006). Mental balance and well-being: Building bridges between Buddhism and Western psychology. American Psychology, 61, 690-701.

Witkiewitz, K., Marlatt, G. A., \& Walker, D. (2005). Mindfulnessbased relapse prevention for alcohol and substance use disorders. Journal of Cognitive Psychotherapy, 19(3), 211-228.

Wong, C. J., Anthony, S., Sigmon, S. C., Mongeon, J. A., Badger, G. J., \& Higgins, S. T. (2004). Examining interrelationships between abstinence and coping self-efficacy in cocainedependent outpatients. Experimental and Clinical Psychopharmacology, 12(3), 190.

Zemore, S. E. (2012). The effect of social desirability on reported motivation, substance use severity, and treatment attendance. Journal of Substance Abuse Treatment, 42(4), 400-412.

Zimmerman, B. J., \& Cleary, T. J. (2006). Adolescents' development of personal agency: The role of self-efficacy beliefs and selfregulatory skill. Self-efficacy Beliefs of Adolescents, 5, 45-69. 